\title{
Sector Well-Being Differences Among UK Police Custody Staff
}

\section{Robert M. Werner-de-Sondberg, Maria Karanika-Murray, Thomas Baguley \& Nicholas Blagden}

Journal of Police and Criminal Psychology

The Official Journal of the Society for Police and Criminal Psychology

ISSN 0882-0783

J Police Crim Psych

DOI 10.1007/s11896-017-9241-1

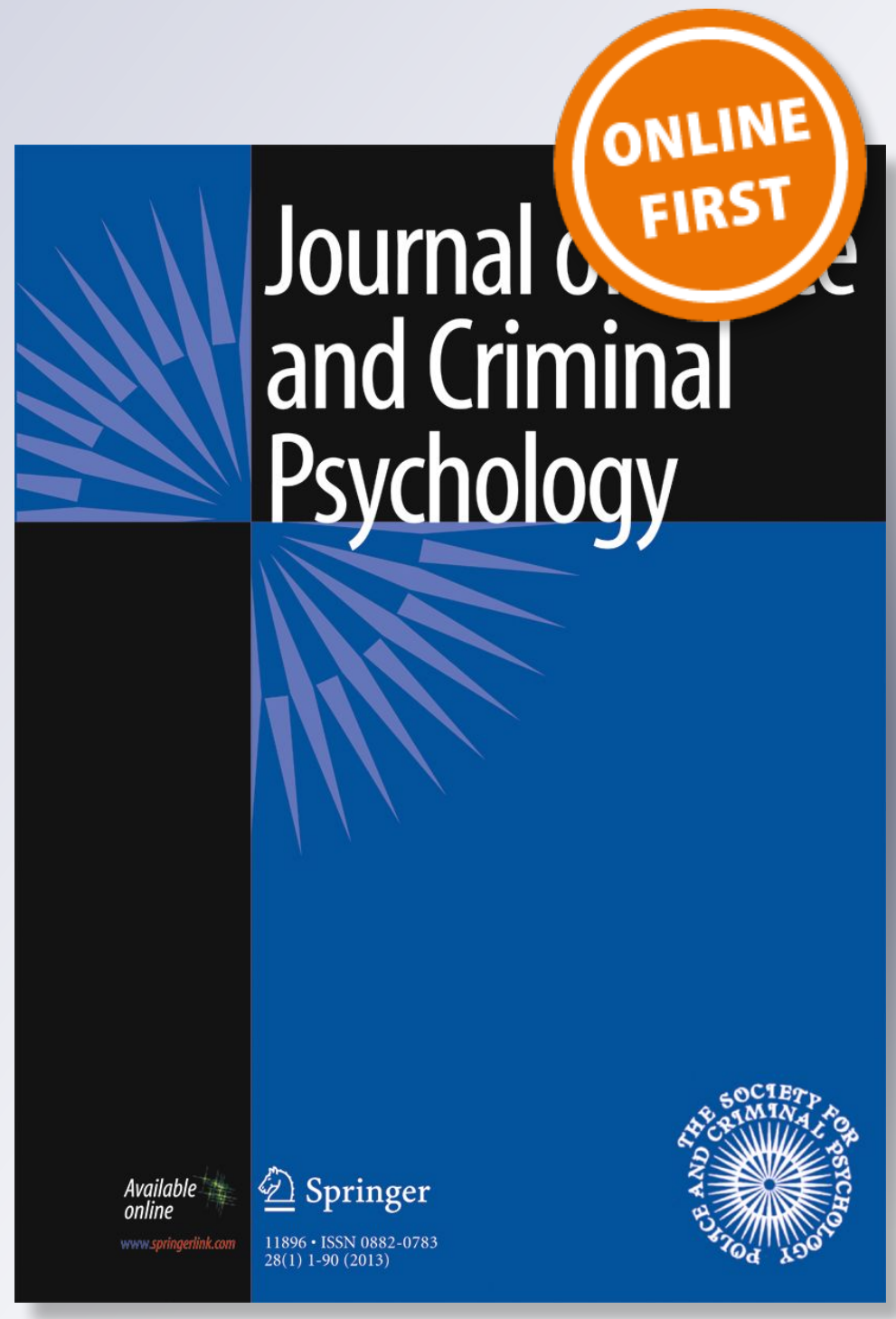

鱼 Springer 
Your article is published under the Creative Commons Attribution license which allows users to read, copy, distribute and make derivative works, as long as the author of the original work is cited. You may selfarchive this article on your own website, an institutional repository or funder's repository and make it publicly available immediately. 


\title{
Sector Well-Being Differences Among UK Police Custody Staff
}

\author{
C. Robert M. Werner-de-Sondberg ${ }^{1}$ (D) $\cdot$ Maria Karanika-Murray $^{1} \cdot$ Thomas Baguley $^{1}$. \\ Nicholas Blagden ${ }^{1}$
}

(C) The Author(s) 2017. This article is an open access publication

\begin{abstract}
The research explores a new model of staff wellbeing across UK police custodial services (public and private). These services are unique for the fact that police sergeant custody officers are supported by detention officers who can be publicly or privately contracted, with the latter providing a heterogeneous mix never previously researched. The model informs a survey approach conducted across four English police forces. Drawing on a diverse literature which compares health and criminal justice professions, this study explores the possibility that private sector detention officers will report lower levels of emotional exhaustion and workplace stress and higher levels of personal accomplishment than their public sector counterparts. Multilevel analyses, supplemented by ANOVA and $t$ tests, detected statistically significant differences for private sector detention officers regarding higher levels of emotional exhaustion and lower levels of personal accomplishment and workplace stress (with the stress result the only one in the predicted direction). However, results should be interpreted as sample specific linked to privately contracted detention officer disquiet with their then employer (since replaced). That said, the results provide a good exploration of the model's utility together with important lessons for model and survey development in the future.
\end{abstract}

The affiliation for where the research was conducted is Birmingham City University, UK.

C. Robert M. Werner-de-Sondberg wernerdesondberg@btinternet.com

1 Psychology Department, Nottingham Trent University, Burton Street, Nottingham, England NG1 4BU, UK
Keywords Criminal justice (police custody and prison corrections) $\cdot$ Employee well-being $\cdot$ Public and private sectors · Organizational culture and climate $\cdot$ Multilevel analysis

\section{Introduction}

Health and criminal justice professions are viewed as analogous in terms of occupational threats to staff well-being (Arnold 2016), yet literature regarding the impact of sector working (public and private) is far from analogous, appearing to favor the private sector for health while equivocating over criminal justice. For health, examples saw greater levels of private sector support, attitudes, and use of evidence-based practice implemented by mental health service providers in the USA (Aarons et al. 2009). Similarly, Heponiemi et al. (2010) reported a comparison of Finnish physicians which saw not only greater levels of positive private sector job attitudes and well-being but also organizational justice and job control than in the public sector. For criminal justice, and especially prison/correctional services, no one sector dominates. For example, in Liebling et al. (2015), while the wholesale transition of HMP Birmingham (in the UK), from the public to private sector in 2011, produced statistically significant improvements in staff quality of life scores for the period 2012 to 2013 (following initial turbulence; exceeding levels for 2011), this was attributed to a combination of sector strengths: public, in terms of experience and a traditionalprofessional approach to the use of authority; private, in terms of more efficient staff deployment, a clearer vision, and innovative and capable management. Other research has been more equivocal. For example, Crewe et al. (2014) draws attention to staff "weight" in terms of the use of authority and power and whether they were heavy or light, absent or present. 
Results across seven UK prisons (two public and five private) suggest that the public sector tends towards "heavy-present" and the private sector "light-absent," both of which exhibit strengths and weaknesses capable of influencing both staff and prisoner well-being (cf. Hulley et al. 2011 regarding differential implications for respect in prisons, where a less positive picture emerged for some prisons in the private sector, while a more mixed picture of strengths and weaknesses emerged for the public sector).

Within UK prison/correctional services, it is worth pointing out that regimes are entirely public or private, including privately led consortia that encompass the third sector (Bell 2013). A UK criminal justice variant is police custodial services where regimes are either entirely public or a mix of public (police) and private (detention officers) sharing the same workplace. In England and Wales, for example, police custody suites are run by police sergeant custody officers (legislatively responsible under the Police and Criminal Evidence Act, 1984), and are assisted in their role by civilian detention officers ${ }^{1}$ whose contracts can be public or private. The impact of such a heterogeneous mix has never previously been researched, despite the fact that where detention officers are privately contracted, there is the possibility that sector differences in terms of organizational culture and climate could impact staff well-being differently (in ways not dissimilar to prison/correctional services). Unfortunately, the absence of research makes it impossible to know if such comparisons are legitimate; although, it is likely that the same concerns about "privatization and the pressures of financial imperatives" are shared by both services (Bell 2013; cf. Genders 2003; Genders and Player 2007). For example, the kinds of sector differences observed at HMP Birmingham are common across English and Welsh prison/correctional services concerning dimensions of culture, confidence in the use of authority, knowledge/experience, and the delivery of safe/reliable regimes (Liebling et al. 2010). Where such factors negatively impact prison staff well-being, there is concern this could undermine staff-prisoner relations (Liebling 2011), with the same also true for police custody. Police and prison/correctional services have also encountered considerable organizational change and the impact of public sector austerity cuts in recent years, both of which have had the potential to affect staff morale.

\section{Culture and Climate Links to Police Custody Staff Well-Being}

Of concern is the difficulty police custody poses as a workplace, with the treatment of prisoners a natural source of public and media attention (e.g., Sgt. Andrews, Wiltshire Police in Macfarlane 2010) - especially involving deaths in police custody (Davies 2010) — and where, consequently, every action

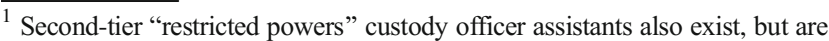
virtually unknown at this time.
}

by staff and prisoners is constantly recorded audibly and visually. While this makes custody staff well-being an important area of research, there is the problem of measuring organizational culture and climate from an integrated perspective (cf. Ehrhart et al. 2014). This integration is important for the fact culture and climate represent the why and what of organizational behavior (Askanasy and Härtel 2014): the "why" in terms of the deep-seated history of the organization, as reflected in its policies, practices, and procedures; the "what" in terms of the meaning employees attribute to these events, policies, practices and procedures and the behaviors they see rewarded, supported and expected. In the language of cause and effect, culture is therefore seen as the cause and climate the effect (Askanasy and Härtel 2014), a distinction made explicit in Glisson and James (2002), where cross-level analyses risked confound if measured one without the other.

Ehrhart et al. (2014) cites three modeled examples of culture and climate integration, with two (Schneider et al. 2011a, b, and Ostroff et al. 2012) providing links to employee wellbeing. The third model is that of Zohar and Hofmann (2012) whose more traditional integration has top-down (deep-layered/espoused) culture contrasting bottom-up (enacted) strategic climate. A final, unpublished example, based its structure on the theory of planned behavior (TPB; Ajzen 1991) and for this reason shares parsimony with the "climcult" model of Schneider et al. (2011b) (Werner-de-Sondberg, 2008). However, this last model was focused on the behavioral outcome of effective communication. The challenge now is to see if it can be applied to well-being.

Until now, research, which integrates organization culture and climate on the topic of policing and prison/correctional services, has been absent from US and UK literature. Culture research dominates, linking poor well-being to traditional, authoritarian elements of occupational and organizational environments, cynicism and emotional detachment, with what might be considered references to climate (i.e., personal efficacy, lack of meaning, purpose, and identity), rarely distinguished as such (Terrill et al. 2003; cf. Arnold 2016; Arnold et al. 2007). While the USA and UK do provide examples of well-being climate research, for prison/correctional services, it is couched in terms of health and safety "risk" (Bevan et al. 2010) and "impact" (Bierie 2012), and for police custody, "hazard exposure" (Houdmont 2013) and "stress" (Houdmont 2014) rather than climate per se.

In England and Wales, evidence that working in police custody can adversely affect well-being comes mainly from two sources: UNISON (2010), who reported results of a 2008 study of police staff which found that detention officers experienced higher levels of stress, more staff shortages and lower levels of workplace safety than other staff roles in the police service and were less likely to recommend their job to others, and Houdmont (2014), whose longitudinal profiling of custody officers' health similarly found heightened levels of officer 
burnout (emotional exhaustion), psychological distress (depression/anxiety), and intention to leave.

These outcomes, though reflective of poor well-being, sit broadly with the mental health definition of well-being used by the World Health Organization (WHO 2011). This sees every individual realizing their potential, coping with the normal stresses of life, working productively and fruitfully, and able to make a contribution to their local community. This is an approach which essentially conceives well-being as a behavioral and/or psychosocial goal attainment of which depends on factors such as low stress, low emotional exhaustion, and personal accomplishment.

\section{Conceptualizing Organizational Climate and Culture Integration}

While organizational culture and climate can be viewed as the why and what of organizational behavior, with shared culture (value and norm-based), the driver for climate in the way employees collectively attribute meaning (control) to what is rewarded, supported, and expected, this level of agreement does not yet extend to climate (cf. James and James 1989; Ehrhart et al. 2014). This debate is far from trivial because individual psychological climate, even when aggregated as organizational climate, is always viewed as the property of the individual traditionally used to measure affective outcomes, whereas shared-level organizational climate is regarded as the property of the organization traditionally used to measure organizational level outcomes. Culture, on the other hand, is more consistently viewed as patterns of shared basic assumptions promoted as templates for employee conduct and behavior (external and internal; e.g., Schein 2010). This sees the two constructs as not only inter-related but also distinctly different (Askanasy and Härtel 2014), thus providing the clear message that to thoroughly understand custody staff well-being (public and private), organizational culture and climate must be fully integrated.

This integration of organization culture and climate found a home in Werner-de-Sondberg (2008). This was important for the fact that it provided two sub-components of organizational culture (behavioral and normative) and a third of organizational climate (control) (all indirect and direct), ${ }^{2}$ able to be applied using a survey. The approach applies the proposition that positive attitudes and norms (culture) promote positive control (climate) and, therefore, the greater likelihood that well-being will be achieved (Askanasy and Härtel 2014). To this end, indirect beliefs inform the rest of the model by first passing through each of their direct counterparts of attitudes to wellbeing, subjective well-being norms, and perceived well-being control (PWC). This then allows them to inform behavioral

\footnotetext{
${ }^{2}$ Necessary for the fact they make different assumptions about the capacity of individuals to access and report them (Francis et al. 2004).
}

and/or psychosocial goal intentions and finally well-being goal outcomes themselves. That said, PWC is also able to predict the outcomes directly, but only to the extent that it provides a proxy for actual well-being control (theorized to be stronger at times when intention is only a weak predictor of outcome, represented as a dashed line in Fig. 1).

This study is original for the fact that it explores a new model of organizational culture and climate integration focused on police custody: (1) staff well-being and (2) sector differences (public and private), both much neglected areas of research. They address the single research question of exploring how and why factors that promote or undermine police custody staff well-being might also explain differences within and between their public and private sector roles.

Given the study's focus on affective outcomes (emotional exhaustion, personal accomplishment, workplace stress), the individual rather than shared-level was used to measure organizational climate (i.e., aggregated psychological climate). Given the absence of compatible research, the intention is to pursue an exploratory study aimed at hypothesis generation focused on sector differences, where the balance of literature suggests the following:

1a: Privately contracted detention officers will report lower levels of emotional exhaustion than publicly contracted detention officers.

1b: Privately contracted detention officers will report higher levels of personal accomplishment and low workplace stress than publicly contracted detention officers.

2a: Privately contracted detention officers will report lower levels of emotional exhaustion than police sergeant custody officers.

2b: Privately contracted detention officers will report higher levels of personal accomplishment and low workplace stress than police sergeant custody officers.

\section{Method}

\section{Participants and Procedure}

In order to explore the study aims, a paper survey was developed and distributed to all police sergeant custody officers (251) and detention officers (272) located across 23 custody units in four English police forces in 2013 (i.e., one where detention officers are publicly contracted; two where detention officers share the same private contractor; and one where the detention officer contractor declined to take part). Eightyone completed surveys were returned (a response rate of $15.5 \%$; with the potential for competing survey fatigue warned at the outset). These responses included police sergeant custody officers (39), detention officers (public $=27$; 
Fig. 1 Conceptual model for police custody staff well-being (Note 3. Includes demographics)

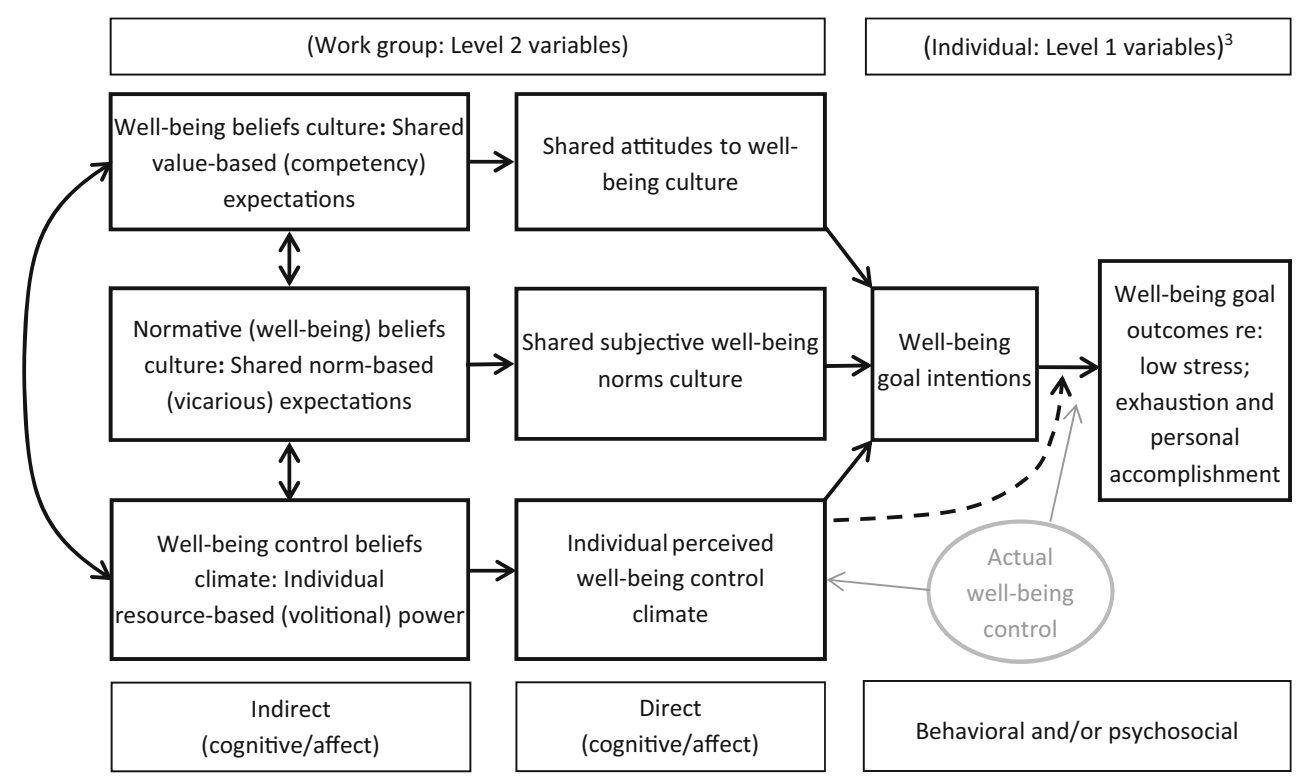

private $=15)$. Custody officer $M_{\text {age }}(42.4$ years $)$ was similar to that of public sector detention officers (41.6 years), although both were much older than private sector detention officers (29.0 years). $M_{\text {tenure in custody }}$ for detention officers (public $=11.1$ years) was longer than for detention officers (private) or custody officers (both 3.7 years). The public sector, e.g., custody officers $(82.1 \%)$ and detention officers (public $=63.0 \%)$ tends to be male dominated relative to private sector detention officers (private $=53.3 \%$ ). Most staff were on full-time contracts, with some part-time contracts for custody officers $(2.6 \%)$ and detention officers (public $=14.8 \%$; private $=0 \%$ ). The right to withdraw, confidentiality of the data, and anonymity of responses were explained to participants at the start of the survey.

\section{Measures}

No case was removed due to standard data cleaning, and both methodological and statistical assumptions regarding the twolevel, nested nature, and multivariate normality/independence of the data were confirmed. For parsimony, all model predictors were bi-directionally worded and scored ranging -2 to +2 . Summed once items had been deleted to maximize alpha reliability, aggregation was justified using intra-class correlation coefficients which allow for weak ICC1s (also providing an effect size and measure of total variance explained by group membership) and strong ICC2s. Demographics were role (detention officer $=0$, custody officer $=1$ ), sector (private $=0$, public $=1)$, contract $($ part-time $=0$, full-time $=1$ ), age (numeric), gender (female $=0$, male $=1$ ), tenure in custody (numeric), and shift when survey completed (days $=0$, earlies $=1$, lates $=2$, nights $=3$, other $=4$ ). The small sample and exploratory nature of the study also saw some alphas reduced from $p<.05$ to $p<.10$. These were anticipated to provide good levels of power in respect of one-way betweengroups ANOVAs (provided effect sizes were large) and independent samples t-tests (provided effect sizes were medium to large), as follows. ${ }^{3}$ With $N$ ranging sector-role to account for group differences, for ANOVA ( $\alpha=0.05)$, these were as follows: $N=60-70$ for $70 \%$ power, and $N=76-80$ for $80 \%$ power; for ANOVA $(\alpha=0.10), N=48-55$ for $70 \%$ power, $N=60-65$ for $80 \%$ power, and $N=80-85$ for $90 \%$ power. With $N$ ranging large-medium size effects, for $t$ test ( $\alpha=0.05$ ), these were as follows: $N=32-78$ for $70 \%$ power, $N=42-102$ for $80 \%$ power, and $56-104$ for $90 \%$ power; for $t$ test $(\alpha=0.10), N=11-27$ for $70 \%$ power, $N=30-74$ for $80 \%$, and $N=42-106$ for $90 \%$ power.

\section{Well-Being Belief Culture}

We used 14 custody officer competencies (Home Office 2003) regarding respect for race and diversity $(\alpha=0.75,95 \% \mathrm{CI}$ $[0.7,0.8])$; effective communication $(\alpha=0.72,95 \%$ CI [0.6, $0.8]$ ); problem solving ( $\alpha=0.71,95 \%$ CI $[0.6,0.8]$ ); personal responsibility ( $\alpha=0.77,95 \%$ CI $[0.7,0.8]$ ); and resilience $(\alpha=0.83,95 \%$ CI $[0.7,0.9])$, with two (i.e., community and customer focus $[\alpha=0.51]$ and planning and organizing $[\alpha=0.59])$ removed due to their low alphas. Although expected to be less familiar to detention officers, they provided an opportunity for both to be assessed using the same scales. For example, "Team members understand other people's views and take them into account, helping them achieve well-being in their daily working life" (anchored "disagree" to "agree").These produced an alpha reliability of $0.92,95 \%$

\footnotetext{
${ }_{3}^{3}$ All power analyses used G*Power (Faul et al., 2007), with effect sizes based on Cohen's (1988) f and d tests as incorporated into online calculators found at www.psychometrica.de/effect_size.html
} 
CI $[0.9,0.9]$ (ICC2 $.9195 \%$ CI $[0.9,0.9]$ and ICC1 $0.4395 \%$ CI $[0.4,0.5]$ ) (a large effect heavily influenced by team membership, accounting for $43 \%$ variance).

\section{Normative (Well-Being) Belief Culture}

We used eight items informed by both the Organizational Culture Inventory (people focused; Balthazard et al. 2006) and a priori (Werner-de-Sondberg, 2008) influences, e.g., "Team members believe the approval of others [and of] linemanager(s) [will] actively help them to achieve well-being in their daily working life" (both anchored disagree to agree). These produced an alpha reliability of $0.71,95 \%$ CI $[0.6$, 0.8 ] (ICC2 $0.58,95 \%$ CI $[0.4,0.7]$ and ICC $10.15,95 \%$ CI $[0.1,0.2]$ ) (a medium to large effect moderately influenced by team membership, accounting for $15 \%$ variance).

\section{Well-Being Control Belief Climate}

We used five items informed by the short version of the Health and Safety Executive's (HSEs) Stress Management Standards Indicator Tool (Cousins et al. 2004) for the following: control; support (colleagues and managers); role; and change; e.g., "Clarity about what my duties and responsibilities are (not assumed) makes achieving well-being in my daily working life" (each anchored "difficult" to "easier"). These produced an alpha reliability of $0.70,95 \%$ CI $[0.58,0.79]$ (ICC2 0.68 , 95\% CI [0.6, 0.8] and ICC1 0.30, 95\% CI [0.2, 0.4]) (a large effect strongly influenced by team membership, accounting for $30 \%$ variance).

\section{Attitudes to Well-Being Culture}

We used two items, e.g., "Team members would find achieving well-being in their daily working life" (experientially "satisfying" and of overall "worth/value"). These produced an alpha reliability of $0.81,95 \%$ CI [0.7, 0.88] (ICC2 0.81 , $95 \%$ CI $[0.7,0.9]$ and ICC $10.68,95 \%$ CI $[0.5,0.8]$ (a very large effect heavily influenced by team membership, accounting for $68 \%$ variance).

\section{Subjective Well-Being Norm Culture}

We used three items reflecting injunctive, descriptive and moral considerations (anchored disagree to agree), e.g., "Team members are urged to/see others/feel they should try to achieve well-being in their daily working life." These produced an alpha reliability of $0.54,95 \%$ CI $[0.33,0.69]$ ICC2 $0.42,95 \%$ CI $[0.2,0.6]$ and ICC1 $0.20,95 \%$ CI $[0.1,0.3])$ (a nearly large effect moderately influenced by team membership, accounting for $20 \%$ variance).

\section{Perceived Well-Being Control Climate}

We used two items reflecting the following: self-efficacy ("Achieving well-being in my daily working life will be" [anchored "very difficult" to "very easy"]) and capability ("I feel confident that I can achieve well-being in my daily working life" [anchored "false" to "true"]). These produced an alpha reliability of $0.81,95 \% \mathrm{CI}[0.7,0.88]$ (ICC2 $0.78,95 \% \mathrm{CI}$ $[0.7,0.9]$ and ICC1 $0.64,95 \%$ CI $[0.5,0.8]$ ) (a very large effect heavily influenced by team membership, accounting for $64 \%$ variance).

\section{Well-Being Intentions}

We used two items, e.g., "I want/intend to achieve wellbeing in my daily working life" (anchored "hardly ever" to "every day"). These produced an alpha reliability of $0.69,95 \%$ CI $[0.52,0.8]$ ICC2 $0.58,95 \%$ CI $[0.4,0.7]$ and ICC $10.41,95 \%$ CI $[0.2,0.6]$ ) (a large effect heavily influenced by team membership, accounting for $41 \%$ variance).

\section{Actual Well-Being Goal Outcomes}

These were selected to support the WHO (2011) mental health definition of well-being, but saw only three of the survey's standardized outcomes and none of the bespoke items have an effect. Workplace stress used the annual HSE item, "In general I find my job?" (anchored "not at all stressful" to "extremely stressful"). Developed by Smith et al. (2000), it was reverse coded to better reflect low workplace stress. Of the 22-item Maslach Burnout Inventory (human services version; Maslach and Jackson, 1996 as cited in Houdmont 2013), only two dimensions were used regarding emotional exhaustion (e.g., "I feel emotionally drained from my work") and personal achievement (e.g., "I feel very energetic"); all anchored "never" to "every day" using a 7-point unipolar scale. These produced alpha reliabilities for emotional exhaustion of $0.91,95 \%$ CI $[0.88,0.94]$ (ICC2 $0.85,95 \%$ CI $[0.8,0.9]$ and ICC $10.38,95 \%$ CI $[0.3,0.5]$ ) (a large effect strongly influenced by team membership, accounting for $38 \%$ variance), and for personal achievement, $0.74,95 \%$ CI $[0.64,0.82]$ (ICC2 $0.59,95 \%$ CI [0.4, $0.7]$ and ICC $10.15,95 \%$ CI $[0.1,0.2]$ ) (a medium effect moderately influenced by team membership, accounting for $15 \%$ variance). Unlike workplace stress, emotional exhaustion could not be reverse scored because of warnings in Demerouti et al. (2010) that low scores on negatively worded exhaustion did not necessarily represent its polar opposite of energy. 
Table 1 Means, standard deviations, and correlations for study demographic variables $(N=81)$

\begin{tabular}{lrlllllll}
\hline & $M$ & SD & 1 & 2 & 3 & 5 & 6 \\
\hline 1. Role & 0.48 & 0.50 & & & & & \\
2. Sector & 0.81 & 0.39 & $0.46^{* *}$ & & & & \\
3. Contract & 0.94 & 0.24 & 0.14 & -0.12 & & & \\
4. Age & 39.67 & 9.99 & $0.27^{*}$ & 0.51 & 0.04 & & & \\
5. Gender & 0.70 & 0.46 & $0.25^{*}$ & 0.18 & $0.40^{* *}$ & $0.33^{* *}$ & & \\
6. Tenure in custody & 5.93 & 5.04 & $-0.45^{* *}$ & 0.22 & -0.10 & $0.41^{* *}$ & 0.07 & \\
7. Shift survey completed & 2.73 & 1.34 & -0.07 & $0.39^{* *}$ & -0.09 & $0.25^{*}$ & 0.12 & $0.28^{*}$ \\
\hline
\end{tabular}

$* p<.05 ; * p<.01$, two-tailed

\section{Results}

Tables 1 and 2 present the means $(M)$, standard deviations (SD), and zero-order correlations $(r)$ for this study.

While cross-level analyses provide insights into the research question how and why factors that promote or undermine police custody staff well-being might also explain differences within and between their public and private sector roles, sample size saw only one statistically significant result for the public sector concerning personal accomplishment, and none at all for the private sector. These cross-level analyses were conducted using hierarchical linear modeling's random coefficient approach (R Core Team 2015). This regression-based approach uses three different models (Finch et al. 2014). The first model (null; random intercept with and without slope) was absent of individual and shared-level fixed effects. The second and third (random intercept and slope for role and sector) added first the individual-level fixed effects of well-being intentions and covariate demographics, in order to control for work group differences, followed by the shared-level fixed effects for culture, and aggregated individual level fixed effects for climate.

For emotional exhaustion (Table 3), it was not until step 3, when all six shared-level culture and climate predictors entered the analysis that the strength of sector differences became apparent. This saw sector differences between custody units $(B=446.8)$ as the largest source of random variance, with less variance due to differences in the constant between custody units $(B=226.8)$, role $(B=116.0)$, and differences in individuals within custody units $(B=96.3)$. The following shared-level predictors emerged as statistically significant, likely to undermine well-being: Positive well-being belief culture (indirect; $B=1.3,95 \%$ CI $[0.1,2.5]$ ); low well-being control belief climate (indirect; $B=-2.09,90 \%$ CI $[-3.9$, $-0.2]$ ); low attitudes to well-being culture (direct; $B=-11.5$, 95\% CI [-21.7, -1.3]); and low perceived well-being control (direct; $B=-5.3,95 \%$ CI $[-10.3,-0.3]$ ). Although some may see positive well-being belief culture a contradiction in terms of the other results, this is not the case if viewed as an example that sometimes "more is less" and where this one positive is rowing against a tide of negative well-being attitudes and control climate (indirect and direct; a metaphor for exhaustion if ever there was one).

Study aims 1a and 2a were explored using two one-way between-groups ANOVAs with 1000 (BCa) bootstrapped samples. While the first and second ANOVAs considered sector and role comparisons separately in terms of four and five groups, respectively, they essentially drew on the same data and so produced very similar statistically significant results (for sector $F[3,72]=2.2, p<.10$ (a medium to large size effect, $f=0.30$; for role $F[4,71]=2.0, p<.10$ (a medium to large size effect, $f=0.3$ ). These saw planned comparisons reveal privately contracted detention officers in two police forces exhibited greater levels of emotional exhaustion $(M=29.4, \mathrm{SD}=10.2)$ than police sergeant custody officers across the same two forces $(M=22.3, \mathrm{SD}=10.1)(90 \% \mathrm{CI}$ for sector $[0.13,14.0]$; for role $[0.34,13.6])$. This provided an exploration of the heterogeneous mix between privately contracted detention officers and police sergeant custody officers (2a), which, though statistically significant, were in the opposite direction to that expected. Differences between privately and publicly contracted detention officers (1a) were statistically non-significant.

For personal accomplishment (Table 4), the strength of sector differences became apparent at Step 1b, also providing an ICC1 which showed a very large proportion of variance (70\%) was due to group membership. This saw sector differences between custody units $(B=148.3)$ as the largest source of random variance, with less variance due to differences in the constant between custody units $(B=86.2)$, individual differences within custody units $(B=36.7)$, and role across custody units $(B=24.8)$. In step 2 , with individual-level demographic and predictor covariates entering the analysis, the largest source of random variance was differences in the constant between custody units $(B=46.8)$, followed by individual differences within custody units $(B=37.4)$. Less variance was explained by sector differences between custody units ( $B=21.3)$, with differences in role between stations having 


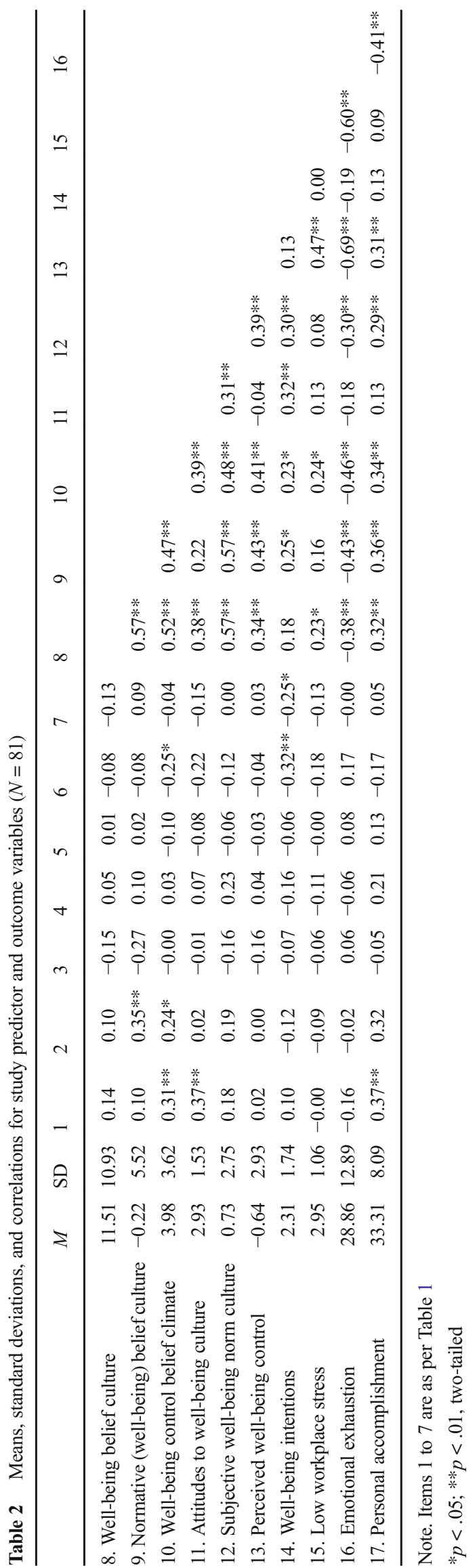

little effect $(B=1.8)$. Sector (public; $B=6.03,90 \%$ CI $[0.7$, $11.5]$ ) and gender (male; $B=2.9,90 \% \mathrm{CI}[0.2,5.6]$ ) emerged as statistically significant individual-level demographic and predictor covariates. In step 3, when all six shared-level culture and climate predictors entered the analysis, the largest sources of random variance were differences in the constant between custody units $(B=68.7)$ and sector $(B=66.8)$. Less variance was explained by individual differences within custody units $(B=35.3)$ with differences in roles between custody units negligible $(B=0.5)$. The following shared-level predictors emerged as statistically significant, likely to promote well-being: sector (public; $B=7.9,90 \%$ CI $[1.8,14.0]$ ); contract (part-time; $B=-5.2,90 \%$ CI $[-9.5,-0.6]$ ); shifts (days; $B=-1.1,90 \%$ CI $[-2.1,-0.1])$; low well-being belief culture (indirect; $B=-0.4,90 \%$ CI $[-0.8,-0.0]$ ); and positive perceived well-being control (direct; $B=1.2,90 \% \mathrm{CI}[0.3,2.2]$ ). Here, one sees a clear contrast with emotional exhaustion, where well-being belief culture was positive, whereas for personal accomplishment, they are low; an example of "less is more" and that sometimes our best efforts work against us.

Study aims $1 \mathrm{~b}$ and $2 \mathrm{~b}$ were explored using two one-way between-groups ANOVAs with 1000 (BCa) bootstrapped samples. The first ANOVA considered sector comparisons and produced a statistically significant difference between public and private sectors, $F[3,72]=4.6, p=.005$ (a large size effect, $f=0.4$ ). Planned comparisons revealed privately contracted detention officers in two police forces exhibited less personal accomplishment $(M=28.0, \mathrm{SD}=8.9)$ than the police sergeant custody officers across the same two forces $(M=35.7, \mathrm{SD}=7.9)(95 \% \mathrm{CI}[1.2,14.4])$. This was also true of the same privately contracted detention officers when compared to police sergeant custody officers in two other forces: (1) $(M=40.7, \mathrm{SD}=2.4)(95 \% \mathrm{CI} 8.3,17.8])$; (2) $(M=33.3$, $\mathrm{SD}=7.6)(95 \% \mathrm{CI} 0.9,10.6])$. This provided a first exploration of difference between privately contracted detention officers and police sergeant custody officers ( $2 b)$, which, though statistically significant, was in the opposite direction to that expected. Differences between privately and publicly contracted detention officers (1b) were statistically non-significant, except for an independent samples t-test which revealed privately contracted detention officers in one force $(M=28.0$, $\mathrm{SD}=9.2$ ) experienced less personal accomplishment than publicly contracted detention officers in another force $(M=31.8, \mathrm{SD}=8.2)(80 \%$ CI $[-7.5,-0.2])(t[39]=-1.3$, $p=.09$, converted from two to one-tailed), approaching a medium size effect $(d=0.4)$, which though statistically significant was in the opposite direction to that expected.

The second ANOVA considered role comparisons and produced a statistically significant difference across detention and custody officer roles, $F[4,71]=4.7, p=.002$ (a large size effect, $f=0.5$ ). Planned comparisons revealed privately contracted detention officers across in two police forces exhibited less personal accomplishment $(M=28.0, \mathrm{SD}=8.9)$ 
Table 3 R analyses: emotional exhaustion (level $1=81$; level $2=23$ )

\begin{tabular}{|c|c|c|c|c|c|c|c|c|c|c|c|c|c|c|}
\hline \multirow[t]{2}{*}{ Variable } & \multicolumn{3}{|c|}{$\begin{array}{l}\text { 1a. Random effects: null } \\
\text { model (intercept only) }\end{array}$} & \multicolumn{3}{|c|}{$\begin{array}{l}\text { 1b. Random effects: null } \\
\text { model (with slope) }\end{array}$} & \multicolumn{4}{|c|}{$\begin{array}{l}\text { 2. Random effects: individual- } \\
\text { level demographic and } \\
\text { predictor covariates }\end{array}$} & \multicolumn{4}{|c|}{$\begin{array}{l}\text { 3. Random effects: individual } \\
\text { and shared-level demographic } \\
\text { and predictor covariates }\end{array}$} \\
\hline & Coefficient ${ }^{\mathrm{a}}$ & $S E$ & $t$ value & Coefficient $\mathrm{t}^{\mathrm{a}}$ & $S E$ & $t$ value & Coefficient $^{\mathrm{a}}$ & $S E$ & $t$ value & $d f$ & Coefficient $^{\mathrm{a}}$ & $S E$ & $t$ value & $d f$ \\
\hline Constant & $27.12 * * *$ & 1.83 & 14.81 & $27.31 * * *$ & 1.68 & 16.27 & $23.18^{*}$ & 9.69 & 2.39 & 8 & $45.57 *$ & 5.67 & 3.11 & 0 \\
\hline Role & & & & & & & -6.11 & 6.03 & -1.01 & 16 & -4.95 & 5.94 & -0.83 & 16 \\
\hline Sector & & & & & & & 1.82 & 6.31 & 0.29 & 16 & -3.68 & 8.50 & -0.43 & 16 \\
\hline Contract & & & & & & & 5.85 & 6.19 & 0.94 & 16 & 7.18 & 5.91 & 1.21 & 16 \\
\hline Age & & & & & & & 0.01 & 0.19 & 0.08 & 16 & 0.12 & 0.19 & 0.62 & 16 \\
\hline Gender & & & & & & & -0.04 & 3.69 & -0.01 & 16 & 0.69 & 3.56 & -0.01 & 16 \\
\hline Tenure in custody & & & & & & & -0.02 & 0.45 & -0.05 & 16 & -0.23 & 0.43 & 0.19 & 16 \\
\hline Shift & & & & & & & 0.59 & 1.33 & 0.44 & 16 & 1.85 & 1.41 & 1.32 & 16 \\
\hline Well-being intentions & & & & & & & -0.64 & 0.92 & -0.70 & 16 & -0.49 & 0.89 & -0.55 & 16 \\
\hline Well-being belief culture ${ }^{\mathrm{b}}$ & & & & & & & & & & & $1.32 *$ & 0.59 & 2.25 & 22 \\
\hline Normative belief culture $^{\mathrm{b}}$ & & & & & & & & & & & 0.62 & 1.19 & 0.52 & 22 \\
\hline Control belief climate ${ }^{\mathrm{b}}$ & & & & & & & & & & & $-2.09^{\#}$ & 1.41 & -1.48 & 22 \\
\hline Well-being attitude culture ${ }^{c}$ & & & & & & & & & & & $-11.54 *$ & 5.01 & -2.30 & 22 \\
\hline Subjective norm culture ${ }^{c}$ & & & & & & & & & & & 1.38 & 2.12 & 0.65 & 22 \\
\hline Well-being control climate ${ }^{c}$ & & & & & & & & & & & $-5.30^{*}$ & 2.48 & -2.14 & 22 \\
\hline Shared L2 variance $(\tau)$ & 26.27 & & & 0.00 & & & 4.10 & & & & 226.83 & & & \\
\hline Role & & & & 134.49 & & & 92.51 & & & & 116.03 & & & \\
\hline Sector & & & & 78.36 & & & 50.24 & & & & 446.84 & & & \\
\hline Individual L1 variance $\left(\sigma^{2}\right)$ & 121.18 & & & 100.80 & & & 113.14 & & & & 96.29 & & & \\
\hline ICC1 & 0.18 & & & 0.00 & & & & & & & & & & \\
\hline$\chi^{2}$ & & & & & & & $4.69^{\mathrm{d}}$ & & & 8 & $13.96^{* \mathrm{~d}}$ & & & \\
\hline
\end{tabular}

${ }^{*} p<.05 ; * * p<.01 ; * * * p<.001 ;{ }^{*} p<.10$

${ }^{\text {a }}$ Coefficients are non-standardized

${ }^{\mathrm{b}}$ Indirect measures

${ }^{\mathrm{c}}$ Direct measures

${ }^{\mathrm{d}}$ Estimated using FML, whereas all other coefficient estimates use RML

than police sergeant custody officers across the same two forces $(M=35.7, \mathrm{SD}=7.9)(95 \% \mathrm{CI}[1.0,14.6])$. This was also true of the same privately contracted detention officers when compared to police sergeant custody officers in two other different forces: (1) $M=39.7, \mathrm{SD}=3.4$ (95\% CI [8.1, 18.0]); (2) $M=33.6, \mathrm{SD}=7.6$ (95\% CI [2.9, 13.7]). This provided a second exploration of difference between privately contracted detention officers and police sergeant custody officers (2b), which though statistically significant was in the opposite direction to that expected. Differences between privately and publicly contracted detention officers (1b) were statistically non-significant.

For low workplace stress (Table 5), it was not until step 3, when all six shared-level culture and climate predictors entered the analysis that the strength of sector differences had effect. This saw the largest sources of random variance were role differences $(B=1.8)$ and sector differences $(B=1.5)$ between custody units. Less variance was explained by individual differences within custody units $(B=0.8)$ and differences in the constant between custody units $(B=0.3)$. The following shared-level predictors emerged as statistically significant, likely to promote well-being: contract (part-time; $B=-0.7,90 \%$ CI $[-1.4,-0.0])$; positive well-being control belief climate (indirect; $B=0.2,90 \% \mathrm{CI}[0.0,0.3]$ ); and positive perceived well-being control (direct; $B=0.3,90 \% \mathrm{CI}$ $[0.0,0.6])$, with this last result supporting the theorized view that when intention is a weak predictor of outcome, perceived well-being control will exert a direct influence on outcome.

Study aims $1 \mathrm{~b}$ and $2 \mathrm{~b}$ were initially explored using two one-way between-groups ANOVAs with 1000 (BCa) bootstrapped samples. However, all results proved statistically non-significant, except for independent sample $t$ tests which revealed privately contracted detention officers in two police forces experienced less workplace stress $(M=3.1, \mathrm{SD}=0.9)$ than police sergeant custody officers in the same two forces $(M=2.3, \mathrm{SD}=0.8)(90 \%$ CIs for sector $[0.1,1.4]$; and for role 
Table 4 R analyses: personal accomplishment (level $1=81$; level $2=23$ )

\begin{tabular}{|c|c|c|c|c|c|c|c|c|c|c|c|c|c|c|}
\hline \multirow[t]{2}{*}{ Variable } & \multicolumn{3}{|c|}{$\begin{array}{l}\text { 1a. Random effects: null } \\
\text { model (intercept only) }\end{array}$} & \multicolumn{3}{|c|}{$\begin{array}{l}\text { 1b. Random effects: null } \\
\text { model (with slope) }\end{array}$} & \multicolumn{4}{|c|}{$\begin{array}{l}\text { 2. Random effects: individual- } \\
\text { level demographic and } \\
\text { predictor covariates }\end{array}$} & \multicolumn{4}{|c|}{$\begin{array}{l}\text { 3. Random effects: individual } \\
\text { and shared-level demographic } \\
\text { and predictor covariates }\end{array}$} \\
\hline & Coefficient ${ }^{\mathrm{a}}$ & $S E$ & $t$ value & Coefficient $\mathrm{t}^{\mathrm{a}}$ & $S E$ & $t$ value & Coefficient $^{\mathrm{a}}$ & $S E$ & $t$ value & $d f$ & Coefficient $^{\mathrm{a}}$ & $S E$ & $t$ value & $d f$ \\
\hline Constant & $33.83 * * *$ & 1.13 & 29.87 & $35.01 * * *$ & 0.91 & 38.61 & $33.27 * * *$ & 6.00 & 5.55 & 8 & $27.63 * *$ & 8.37 & 3.30 & 6 \\
\hline Role & & & & & & & 2.59 & 2.88 & 0.90 & 16 & 2.88 & 2.85 & 1.01 & 16 \\
\hline Sector & & & & & & & $6.03^{\#}$ & 4.19 & 1.44 & 16 & $7.89^{\#}$ & 4.71 & 1.68 & 16 \\
\hline Contract & & & & & & & -3.83 & 3.45 & -1.11 & 16 & $-5.15^{\#}$ & 3.44 & -1.50 & 16 \\
\hline Age & & & & & & & 0.00 & 0.11 & 0.00 & 16 & -0.03 & 0.11 & -0.24 & 16 \\
\hline Gender & & & & & & & $2.92^{\#}$ & 2.07 & 1.41 & 16 & 2.28 & 2.04 & 1.12 & 16 \\
\hline Tenure in Custody & & & & & & & -0.20 & 0.25 & -0.79 & 16 & -0.14 & 0.25 & -0.58 & 16 \\
\hline Shift & & & & & & & -0.91 & 0.72 & -1.26 & 16 & $-1.10^{\#}$ & 0.78 & -1.41 & 16 \\
\hline Well-being intentions & & & & & & & -0.33 & 0.51 & -0.65 & 16 & -0.70 & 0.52 & -1.34 & 16 \\
\hline Well-being belief culture ${ }^{\mathrm{b}}$ & & & & & & & & & & & $-0.43^{\#}$ & 0.31 & -1.39 & 22 \\
\hline Normative belief culture $^{\mathrm{b}}$ & & & & & & & & & & & -0.75 & 0.63 & -1.20 & 22 \\
\hline Control belief climate ${ }^{\mathrm{b}}$ & & & & & & & & & & & $1.21^{\#}$ & 0.75 & 1.62 & 22 \\
\hline Well-being attitude culture ${ }^{\mathrm{c}}$ & & & & & & & & & & & 2.37 & 2.65 & 0.90 & 22 \\
\hline Subjective norm culture $^{\mathrm{c}}$ & & & & & & & & & & & 0.75 & 1.10 & 0.68 & 22 \\
\hline Well-being control climate $^{c}$ & & & & & & & & & & & 0.93 & 1.32 & 0.70 & 22 \\
\hline Shared L2 variance $(\tau)$ & 10.65 & & & 86.20 & & & 46.77 & & & & 68.68 & & & \\
\hline Role & & & & 24.80 & & & 1.84 & & & & 0.45 & & & \\
\hline Sector & & & & 148.29 & & & 21.29 & & & & 66.75 & & & \\
\hline Individual L1 variance $\left(\sigma^{2}\right)$ & 44.88 & & & 36.69 & & & 37.37 & & & & 35.27 & & & \\
\hline $\mathrm{ICC} 1$ & 0.19 & & & 0.70 & & & & & & & & & & \\
\hline$\chi^{2}$ & & & & & & & $13.86^{\mathrm{d}}$ & & & 8 & $11.12^{\mathrm{d}}$ & & & \\
\hline
\end{tabular}

${ }^{*} p<.05 ; * * p<.01 ; * * * p<.001 ;{ }^{*} p<.10$

${ }^{\text {a }}$ Coefficients are non-standardized

${ }^{\mathrm{b}}$ Indirect measures

${ }^{\mathrm{c}}$ Direct measures

${ }^{\mathrm{d}}$ Estimated using FML, whereas all other coefficient estimates use RML

$[0.2,1.4])(t[19]=1.95, p=.03$, one-tailed $)$, a large-sized effect $(d=0.9)(2 \mathrm{~b})$. These were the first and only statistically significant results that were expected. In contrast, differences between privately and publicly contracted detention officers (1b) were statistically non-significant.

\section{Discussion}

\section{Theoretical Implications}

These results address research question desires to explain differences within and between public and private sector roles and of exploring an integrated model of organization culture and climate, which conceives well-being as a behavioral and/ or psychosocial goal, attainment of which depends on factors such as low stress, low emotional exhaustion, and personal accomplishment; an approach that proved successful in terms of exposing considerable disquiet among privately contracted detention officers such that predictors of emotional exhaustion and personal accomplishment were less reflective of wellbeing than expected. This fits with the general prison/ correctional literature which suggests strengths and weaknesses of public and private sectors are more mixed than might have been imagined, and where the private sector is sometimes less positive than might be suggested (Hulley et al. 2011; cf. Crewe et al. 2014).

That said, while the finding of private detention officer disquiet exerted a strong and very specific influence, other findings were important for their more general messages about well-being. For emotional exhaustion, this concerned the more is less metaphor of positive well-being belief culture rowing against the tide of negative well-being attitudes and control climate (indirect and direct), a result which fits with policing and prison/correctional services literature which links poor well-being to traditional, authoritarian culture in terms 
Table 5 R analyses: low workplace stress (level $1=81$; level $2=23$ )

\begin{tabular}{|c|c|c|c|c|c|c|c|c|c|c|c|c|c|c|}
\hline \multirow[t]{2}{*}{ Variable } & \multicolumn{3}{|c|}{$\begin{array}{l}\text { 1a. Random effects: null } \\
\text { model (intercept only) }\end{array}$} & \multicolumn{3}{|c|}{$\begin{array}{l}\text { 1b. Random effects: null } \\
\text { model (with slope) }\end{array}$} & \multicolumn{4}{|c|}{$\begin{array}{l}\text { 2. Random effects: individual- } \\
\text { level demographic and } \\
\text { predictor covariates }\end{array}$} & \multicolumn{4}{|c|}{$\begin{array}{l}\text { 3. Random effects: individual } \\
\text { and shared-level demographic } \\
\text { and predictor covariates }\end{array}$} \\
\hline & Coefficient $^{\mathrm{a}}$ & $S E$ & $t$ value & Coefficient $^{\mathrm{a}}$ & $S E$ & $t$ value & Coefficient $^{\mathrm{a}}$ & $S E$ & $t$ value & $d f$ & Coefficient $^{\mathrm{a}}$ & $S E$ & $t$ value & $d f$ \\
\hline Constant & $3.07 * * *$ & 0.16 & 19.37 & $3.03 * * *$ & 0.14 & 21.31 & $4.20 * * *$ & 0.81 & 5.15 & 8 & $4.20 * *$ & 1.21 & 3.45 & 6 \\
\hline Role & & & & & & & -0.44 & 0.52 & -0.85 & 16 & -0.64 & 0.60 & -1.06 & 16 \\
\hline Sector & & & & & & & 0.32 & 0.51 & 0.63 & 16 & 0.44 & 0.63 & 0.70 & 16 \\
\hline Contract & & & & & & & -0.55 & 0.52 & -1.06 & 16 & $-0.74^{\#}$ & 0.54 & -1.37 & 16 \\
\hline Age & & & & & & & -0.01 & 0.02 & -0.70 & 16 & -0.02 & 0.02 & -1.29 & 16 \\
\hline Gender & & & & & & & 0.35 & 0.32 & 1.10 & 16 & 0.38 & 0.33 & 1.19 & 16 \\
\hline Tenure in Custody & & & & & & & $-0.05^{\#}$ & 0.04 & -1.39 & 16 & -0.03 & 0.04 & -0.87 & 16 \\
\hline Shift & & & & & & & -0.05 & 0.11 & -0.44 & 16 & -0.08 & 0.13 & -0.60 & 16 \\
\hline Well-being intentions & & & & & & & -0.03 & 0.08 & -0.35 & 16 & -0.03 & 0.08 & -0.35 & 16 \\
\hline Well-being belief culture ${ }^{\mathrm{b}}$ & & & & & & & & & & & -0.01 & 0.05 & -0.21 & 22 \\
\hline Normative belief culture $^{\mathrm{b}}$ & & & & & & & & & & & -0.07 & 0.11 & -0.66 & 22 \\
\hline Control belief climate ${ }^{b}$ & & & & & & & & & & & $0.17^{\#}$ & 0.13 & 1.38 & 22 \\
\hline Well-being attitude culture ${ }^{c}$ & & & & & & & & & & & 0.02 & 0.40 & 0.05 & 22 \\
\hline Subjective norm culture $^{\mathrm{c}}$ & & & & & & & & & & & -0.12 & 0.19 & -0.64 & 22 \\
\hline Well-being control climate ${ }^{c}$ & & & & & & & & & & & $0.31^{\#}$ & 0.22 & 1.41 & 22 \\
\hline Shared L2 variance $(\tau)$ & 0.19 & & & 0.00 & & & 0.00 & & & & 0.28 & & & \\
\hline Role & & & & 0.83 & & & 1.07 & & & & 1.76 & & & \\
\hline Sector & & & & 0.24 & & & 0.24 & & & & 1.54 & & & \\
\hline Individual L1 variance $\left(\sigma^{2}\right)$ & 0.95 & & & 0.79 & & & 0.79 & & & & 0.80 & & & \\
\hline ICC1 & 0.17 & & & 0.00 & & & & & & & & & & \\
\hline$\chi^{2}$ & & & & & & & $6.58^{\mathrm{d}}$ & & & 8 & $9.29^{\mathrm{d}}$ & & & 6 \\
\hline
\end{tabular}

${ }^{*} p<.05 ; * * p<.01 ; * * * p<.001 ;{ }^{*} p<.10$

${ }^{\text {a }}$ Coefficients are non-standardized

${ }^{\mathrm{b}}$ Indirect measures

${ }^{\mathrm{c}}$ Direct measures

${ }^{\mathrm{d}}$ Estimated using FML, whereas all other coefficient estimates use RML

of occupational and organizational environments, cynicism, and emotional detachment (Terrill et al. 2003; cf. Arnold 2016; Arnold et al. 2007).

By way of contrast, personal accomplishment concerned the less is more antithesis of low well-being belief culture, where sometimes our best efforts work against us, but in this sample enjoys the shared strength of working in the public sector, on part-time contracts, conventional days rather than shifts, and positive control climate; a theme shared for low workplace stress concerning part-time contracts and positive control climate (indirect and direct). The important point is that these results could not have emerged were if not for the integrated model of organization culture and climate. A particular strength being the inclusion of cultural sub-components (indirect and direct), which together with well-being control climate (indirect and direct), suggests value-based attitudes to well-being are statistically significant, whereas norm- based sub-components are not, a finding which cautions against measuring culture as a single construct.

\section{Practical Implications}

Privately contracted detention officer disquiet should be seen as sample specific. This is because their then employer has since been replaced, suggesting the result may be atypical and, therefore, meriting further research (though emphasizing the importance of differential sub-cultures [Arnold 2016; cf. Salas et al. 2014]). The same applies to the fact that there was no statistical difference between publicly and privately contracted detention officers concerning emotional exhaustion (1a) and low workplace stress (1b), where it is likely that private detention officer disquiet was also having an effect.

The exploratory nature of this study should serve to emphasize that development of the integrated model of organization culture and climate is far from complete. This includes the 
need to validate the following: well-being belief culture, founded on value-based competencies (since replaced by decision making, leadership [i.e., leading change, people and managing performance], professionalism, public service and working with others in Skills for Justice 2013); normative culture (indirect and direct) and the lack of predictors concerning vicarious and subjective norms; and control belief climate concerning volitional resource-based power, as informed by HSE Stress Management Standards (MacKay et al. 2004), which some (e.g., Patmore 2006) have criticized as atheoretical.

In terms of well-being outcomes, mention needs to be made of the fact that no items currently exist which capture the WHO (2011) mental health definition of well-being in terms of both behavioral and/or psychosocial factors and the possibility of balancing positive and negative well-being influences (Tetrick, Quick \& Gilmore 2012). This issue also questions use of the Maslach Burnout Inventory with its negatively worded emotional exhaustion items, which risks conflating well-being with burnout, precisely why workplace stress was recoded. For this reason, future research should use the Oldenburg Burnout Inventory (Demerouti et al. 2010) whose two-dimensional and bi-directionally worded items make it easier to code for energy and engagement, as a better match for well-being.

Applications of the model for practical purposes have scope to explain/predict any number of workplace behaviors and goals (people and task focused), though benefitting larger organizations in terms of cross-level analysis. For example, the outsourcing and commissioning of occupational roles to sectors (community, private and voluntary) are now so commonplace within the UK public sector, e.g., armed forces, criminal justice, education, and health that any or all could benefit from this approach.

\section{Study Limitations}

Despite limitations of a cross-sectional design and relatively small sample, there were good levels of power, as supported by the medium- to large-sized effects highlighted by the results and a priori power analyses. The study's access to 23 custody units across four police forces was yet a further strength, thus providing invaluable multilevel lessons for how the model and survey might be improved in future.

Given the caution that privately contracted detention officer disquiet is sample specific and merits further research, questions arise regarding the generalizability of results. Here, it is argued that the results satisfy literal and/or theoretical replication (Yin 2014), i.e., able to predict similar results and/or anticipated contrasting results, in ways akin to nomothetic generalization (Shiveley and Micso 2009; cf. Buchanan 2012 regarding other forms of generalization which are similarly neither discrete nor mutually exclusive). It is also the case that until now precise correspondence between police custodial and prison/correctional staff was unknown and only assumed to be similar (Arnold et al. 2007). In these results, however, that correspondence has shown itself to be analogous in terms of mixed sector strengths and weaknesses across all three well-being outcomes and, in particular, concerning the more is less and less is more contrasts. The results serve to emphasize the fact that officer sub-culture (police custody and prison/correctional) is neither distinctive nor undifferentiated (Arnold 2016).

For some, the sole use of a self-report survey is a distinct limitation, though well suited to tap the kinds of internal states sought by this research. No longer viewed as automatically common method biased (e.g., Brannick et al. 2010) measures, procedural and statistical, were taken to avoid survey bias where possible.

Finally, the model and survey needs to be tested in three ways: (1) longitudinally, in order to explore causal relations; (2) across a much larger sample, in order to better understand the strength of cross-level analyses; and (3) across many more, different dimensions of well-being, in order to be clear about the model's predictive power and validity.

\section{Conclusion}

This study successfully explores use of an integrated model of organization culture and climate for the purpose of understanding sector well-being differences across 23 custody units in four English police forces. This saw the model conceptualize well-being as a behavioral and/or psychosocial goal, based on the WHO (2011) mental health definition of well-being, predicted by two sub-components of culture (value and normbased) and single control factor for climate. Findings detected considerable disquiet among privately contracted detention officers specifically and some important messages about well-being generally.

Acknowledgements The authors give thanks to Professor Craig Jackson for his tangible support with the data collection.

Open Access This article is distributed under the terms of the Creative Commons Attribution 4.0 International License (http:// creativecommons.org/licenses/by/4.0/), which permits unrestricted use, distribution, and reproduction in any medium, provided you give appropriate credit to the original author(s) and the source, provide a link to the Creative Commons license, and indicate if changes were made.

\section{References}

Aarons GA, Sommerfeld DH, Walrath-Greene CM (2009) Evidencebased practice implementation: the impact of public versus private sector organization type on organizational support, provider attitudes, and adoption of evidence-based practice. Implement Sci 4: 83. ss. doi:10.1186/1748-5908-4-83 
Ajzen I (1991) The theory of planned behavior. Organ Behav Hum Decis Process 50:179-211. doi:10.1016/0749-5978(91)90020-T

Arnold H (2016) The prison officer. In: Jewkes Y, Crewe B, Bennett J (eds) Handbook on prisons, 2nd edn. Routledge, Abingdon, pp 265-283

Arnold H, Liebling A, Tait S (2007) Prison officers and prison culture. In: Jewkes Y (ed) Handbook on prisons. Routledge, Abingdon, pp 471495

Askanasy NM, \& Härtel CEJ (2014) Positive and negative affective climate and culture: the good, the bad, and the ugly. In B. Schneider, \& K. M. Barbera (Eds.). The Oxford handbook of organizational climate and culture [Oxford Handbooks Online]. doi: 10.1093/ oxfordhb/9780199860715.013.0008

Balthazard PA, Cooke RA, Potter RE (2006) Dysfunctional culture, dysfunctional organization: capturing the behavioral norms that form organizational culture and drive performance. J Manag Psychol 21: 709-732. doi:10.1108/02683940610713253

Bell E (2013) Punishment as politics: the penal system in England and Wales. In: Ruggiero V, Ryan M (eds) Punishment in Europe: a critical anatomy of penal systems. Palgrave Macmillan, Basingstoke, pp 58-85

Bevan A, Houdmont J, Menear N (2010) The Management Standards Indicator Tool and the estimation of risk. Occup Med 60:525-553. doi:10.1093/occmed/kqq109

Bierie DM (2012) The impact of prison conditions on staff well-being. Int J Offender Ther Comparative Criminol 56:81-95. doi:10.1177/ $0306624 X 10388383$

Brannick MT, Chan D, Conway JM, Lance CE, Spector PE (2010) What is method variance and how can we cope with it? A panel discussion. Organ Res Methods 13:407-420. doi:10.1177/ 1094428109360993

Buchanan DA (2012) Case studies in organizational research. In: Symon G, Cassell C (eds) Qualitative organizational research: core methods and current challenges. Sage, London, pp 351-370

Cohen J (1988) Statistical power analysis for the behavioral sciences, 2nd edn. Erlbaum, Hillsdale

Cousins R, Mackay CJ, Clarke SD, Kelly C, Kelly PJ, McCaig RH (2004) 'Management Standards' and work-related stress in the UK: practical development. Work tress 18:113-136. doi:10.1080/ 02678370410001734322

Crewe B, Leibling A, Hulley S (2014) Heavy-light, absent-present: rethinking the 'weight' of imprisonment. Br J Sociol 65:387-410. doi: $10.1111 / 1468-4446.12084$

Davies C (2010) Deaths in police custody since 1998, 333; officers convicted, none. The Guardian. Retrieved from http://www.guardian. co.uk/uk/2010/dec/03/deaths-police-custody-officers-convicted

Demerouti E, Mostert K, Bakker AB (2010) Burnout and work engagement: a thorough investigation of the independency of both constructs. J Occup Health Psychol 15:209-222

Ehrhart MG, Schneider B, Macey WH (2014) Organizational climate and culture: an introduction to theory, research, and practice. Routledge, New York

Faul F, Erdfelder E, Lang A, Buchner A (2007) G*Power 3: a flexible statistical power analysis program for the social, behavioral, and biomedical sciences. Behav Res Methods 39:175-191. doi:10. 3758/BF03193146

Finch WH, Bolin JE, Kelley K (2014) Multilevel modeling using R. CRC Pressm, Boca Raton

Francis JJ, Johnston M, Eccles MP, Grimshaw J, Kaner EFS (2004) Measurement issues in the theory of planned behaviour: a supplement to the manual for constructing questionnaires based on the theory of planned behaviour. University of Newcastle upon Tyne, UK: Centre for Health Services Research. Retrieved from http:// www.rebeqi.org/ViewFile.aspx?itemID $=219$

Genders E (2003) Privatisation and innovation - rhetoric and reality: the development of a therapeutic community prison. Howard J 42:137157. doi:10.1111/1468-2311.00272
Genders E, \& Player E (2007) The commercial context of criminal justice: prison privatisation and the perversion of purpose. Criminal Law Review, Jul, 513-529. Retrieved from https://www. researchgate.net/publication/32894904

Glisson C, James LR (2002) The cross-level effects of culture and climate in human service teams. J Organ Behav 23:767-794. doi:10.1002/ job. 162

Heponiemi T, Kuusio H, Sinervo T, Elovainio M (2010) Job attitudes and well-being among public vs. private physicians: organizational justice and job control as mediators. Eur J Pub Health 21:520-525. doi: 10.1093/eurpub/ckq107

Home Office (2003). Circular 14: performance and development reviews. Retrieved from http://webarchive.nationalarchives.gov. uk/+/http:/www.homeoffice.gov.uk/about-us/home-office-circulars/ circulars-2003/014-2003/

Houdmont J (2013) UK police custody officers' psychosocial hazard exposures and burnout. Policing Int J Police Strat Manage 36:620 635. doi:10.1108/PIJPSM-11-2012-0109

Houdmont J (2014) Custody officers' stress-related working conditions: relations with health and organisational effectiveness. Final report to the Sergeants Central Committee, Police Federation of England and Wales. Retrieved from http://www.polfed.org/documents/SCC Custody_Study_Final_Report_200514.pdf

Hulley S, Liebling A, Crewe B (2011) Respect in prisons: prisoners' experiences of respect in public and private sector prisons. Criminol Crim Justice 12:3-23. doi:10.1177/1748895811423088

James LA, James LR (1989) Integrating work environment perceptions: explorations into the measurement of meaning. J Appl Psychol 74: 739-751 Retrived from: http://www.jwalkonline.org/docs/Grad\% 20Classes/Survey/ articles/psyclimate/noted/james\%20and\% 20james.pdf

Liebling A (2011) Distinctions and distinctiveness in the work of prison officers: legitimacy and authority revisited. Eur J Criminol 8:484 499. doi:10.1177/1477370811413807

Liebling A, Crewe B, Hulley S, \& McLean C (2010) Values, practices and outcomes in public and private sector corrections: full research report. ESRC End of Award Report, RES-062-23-0212. Swindon: ESRC. Retrieved from http://www.esrc.ac.uk/my-esrc/grants/RES-062-230212/outputs/Read/39906f76-f9ab-43e2-83a4-d356969c9959

Liebling A, Schmidt B, Crewe B, Auty K, Armstrong R, Akoensi T, Kant D, Ludlow A, \& Levins A (2015) Birmingham prison: the transition from public to private sector and its impact on staff and prisoner quality of life - a three-year study. NOMS Analytic summary. Retrieved from https://www.gov.uk/government/uploads/system/ uploads/attachment data/file/449351/birmingham-prison-3-study.pdf

Macfarlane J (2010) Police sergeant jailed for throwing woman in cell 'punched and kicked civil servant in separate attack', The Daily Mail. Retrieved from: http://www.dailymail.co.uk/news/article1311229/Police-sergeant-punched-kicked-Civil-servant-tellsprevious-attack-officer-jailed-assaulting-woman.html

MacKay CJ, Cousins R, Kelly PJ, Lee S, McCaig RA (2004) 'Management Standards' and work-related stress in the UK: policy background and science. Work Stress 18:91-112. doi:10.1080/ 02678370410001727474

Ostroff C, Kinicki AJ, \& Muhammad RS (2012). Organizational culture and climate. In NW Schmitt \& S Highhouse (Eds) Handbook of psychology, Vol 12: Industrial and organizational psychology, 2nd edn. Wiley, Hoboken, pp 643-676

Patmore A (2006) The truth about stress. Atlantic Books, London

R Core Team (2015) $R$ : a language and environment for statistical computing. R Foundation for Statistical Computing, Vienna, Austria. Retrieved from https://www.R-project.org/

Salas E, Salazar MR, Feitosa J, Kramer WS (2014). Collaboration and conflict in work teams. In B Schneider, \& KM Barbera (Eds.). The Oxford handbook of organizational climate and culture [Oxford 
Handbooks Online]. doi: 10.1093/oxfordhb/9780199860715.013. 0020

Schein EH (2010) Organizational culture and leadership, 4th edn. JosseyBass, San Francisco

Schneider B, Ehrhart MG, \& Macey WA (2011a) Organizational climate research: Achievements and the road ahead. In NM Ashkanasy, CPM Wilderom, \& MF Paterson (Eds) Handbook of organizational culture and climate, 2nd edn. Sage, Thousand Oaks, pp 29-49

Schneider B, Ehrhart MG, \& Macey WA (2011b) Perspectives on organizational climate and culture. In S Zedeck (Ed) APA handbook of industrial and organizational psychology: Vol. 1. Building and developing the organization. American Psychological Associationpp, Washington, DC, pp 373-414

Shiveley JM, Micso T (2009) Reclaiming generalizations in social studies education. Soc Stud Res Pract 4:73-78 Retrieved from http://www. socstrp.org/issues/PDF/4.2.6.pdf

Skills for Justice, (2013). Policing professional framework. Retrieved from http://www.sfjuk.com/ppf/

Smith A, Johal S, Wadsworth E, Davey Smith G, Peters T (2000) The scale of perceived stress at work: the Bristol stress and health at work study. Contract research report 265/2000. HSE Books, Sudbury
Terrill W, Paoline EA III, Manning PK (2003) Police culture and coercion. Criminology 41:1003-1034. Doi:10.1111/j.1745-9125.2003. tb01012.x

Tetrick LE, Quick JC, \& Gilmore PL (2012) Research in organizational interventions to improve well-being: Perspectives on organizational change and development. In C Biron, M Karanika-Murray, \& CL Cooper (Eds) Improving organizational interventions for stress and well-being . Routledge, Hove, pp 59-76

UNISON (2010). In detention. A research report on police custody staff for UNISON from Incomes Data Services. Retrieved from http:// www.unison.org.uk/acrobat/19505.pdf

Werner-de-Sondberg, CRM (2008). British police service performance diagnosis: A critical realist (quantitative) perspective. Unpublished doctoral dissertation, University of East London, UK

World Health Organisation (2011). Mental health: a state of well-being. Retrieved from http://www.who.int/features/factfiles/mental_health/ en/

Yin RK (2014) Case study research: design and methods, 5th edn. Sage, London

Zohar, D, \& Hofmann, DA (2012) Organizational culture and climate. In SWJ Kozlowski (Ed) The handbook of industrial and organizational psychology . Oxford University Press, Oxford, pp. 643-666 